\title{
Real-World Use of Once-Weekly Semaglutide in Type 2 Diabetes: Results from the SURE UK Multicentre, Prospective, Observational Study
}

\author{
Patrick Holmes (D) - Heather Elizabeth Bell · Karan Bozkurt • \\ Andrei-Mircea Catarig · Alice Clark · Alena Machell · Thozhukat Sathyapalan
}

Received: June 18, 2021 / Accepted: August 9, 2021 / Published online: September 25, 2021

(C) The Author(s) 2021

\section{ABSTRACT}

Introduction: Once-weekly (OW) semaglutide was associated with clinically relevant improvements in glycaemic control and body weight versus comparators in the SUSTAIN randomised controlled trials (RCTs). SURE UK, which is one of a series of individual studies that comprise the SURE programme, evaluated the use of OW semaglutide in a real-world

Supplementary Information The online version contains supplementary material available at https:// doi.org/10.1007/s13300-021-01141-8.

P. Holmes ( $\square)$

St George's Medical Practice, Yarm Road, Darlington DL2 1BY, UK

e-mail: patrickholmes@nhs.net

H. E. Bell

Old School Surgery, Greenisland, Northern Ireland, UK

K. Bozkurt

Novo Nordisk Ltd, London, UK

A.-M. Catarig · A. Clark

Novo Nordisk A/S, Søborg, Denmark

A. Machell

Egremont Medical Centre, Wallasey, UK

T. Sathyapalan

Academic Diabetes, Endocrinology and Metabolism, Hull York Medical School, University of Hull, Hull, UK patient population with type 2 diabetes (T2D) in the UK.

Methods: In this prospective, observational study, adults ( $\geq 18$ years) with $\geq 1$ documented glycated haemoglobin $\left(\mathrm{HbA}_{1 \mathrm{c}}\right)$ value $\leq$ 12 weeks before semaglutide initiation were enrolled. The primary endpoint was change in $\mathrm{HbA}_{1 \mathrm{c}}$ from baseline to end of study (EOS; 30 weeks, although due to the COVID19 pandemic, visits up to week 52 were permitted). Secondary endpoints included change in body weight, waist circumference and patient-reported outcomes (PROs). Physicians were to report all episodes of documented or severe hypoglycaemia, fatal events, serious adverse drug reactions, pregnancies and adverse events (AEs) in foetuses/newborn infants; other AEs during the study period could be reported on a voluntary basis.

Result: The estimated mean change in $\mathrm{HbA}_{1 \mathrm{c}}$ from baseline to EOS was - $16.3 \mathrm{mmol} / \mathrm{mol}$ [95\% confidence interval (CI): - 18.22, - 14.37] ( $-1.5 \%$-points [95\% CI $-1.67,-1.31]$; $p<0.0001)$ among the 171 enrolled patients who completed the study on treatment. Mean body weight change was - $5.8 \mathrm{~kg}(95 \% \mathrm{CI}$ $-6.75,-4.94 ; p<0.0001)$. Sensitivity analyses showed similar results. Improvements were also observed in other secondary endpoints, including PROs. No new safety concerns were identified with semaglutide treatment.

Conclusion: Patients receiving OW semaglutide experienced statistically significant and 
clinically relevant reductions from baseline in $\mathrm{HbA}_{1 \mathrm{c}}$ and body weight. These results are in line with those of the SUSTAIN RCTs and support the use of OW semaglutide in routine clinical practice in adults with T2D in the UK.

Trial registration: ClinicalTrials.gov Identifier NCT03876015.

Keywords: Type 2 diabetes; Glucagon-like peptide-1 receptor agonist; Semaglutide; Realworld evidence

\section{Key Summary Points}

\section{Why carry out this study?}

In the SUSTAIN phase 3 clinical trial programme, once-weekly (OW) semaglutide demonstrated superior, clinically relevant glycaemic and body weight reductions versus a wide range of comparators in people with type 2 diabetes (T2D).

Real-world evidence on the use of OW semaglutide in routine clinical practice is needed to augment these clinical trial findings.

The SURE programme, which was conducted across 10 countries, investigated the use of OW semaglutide in patients with T2D in real-world clinical practice.

Here, we report the results of SURE UK, a prospective, multicentre, single-arm, open-label, observational study.

\section{What was learned from the study?}

In real-world clinical practice, patients receiving OW semaglutide experienced statistically significant and clinically relevant glycaemic and body weight reductions; no new safety concerns were observed.

\section{INTRODUCTION}

Type 2 diabetes (T2D) is a significant health problem globally, with a high prevalence in many countries including the UK; Diabetes UK estimated the prevalence of T2D in the UK in 2019 at 3.9 million [1]. Treatment guidelines for T2D-including those from the National Institute for Health and Care Excellence (NICE), the American Diabetes Association (ADA) and the European Association for the Study of Diabetes (EASD)-emphasise the need for continuous, patient-centred care that extends beyond glycaemic control [2-5]. Multifactorial risk-reduction strategies that cover a treatment's safety profile and associated patient-reported outcomes (PROs), such as patient preference, are recommended to delay or prevent complications while maintaining quality of life [2-5]. Of the treatment options recommended by guidelines, glucagon-like peptide-1 receptor agonists (GLP-1RAs), such as liraglutide, dulaglutide and semaglutide, have been associated with several benefits, including improved glycaemic control, reduced body weight, cardiorenal protection [6-10] and a low risk of hypoglycaemia [8, 11], and are recommended as second-line therapy by the ADA/EASD guidelines [2]. According to the NICE guidelines (undergoing revision at the time of writing), GLP-1RA therapy can be continued only if the person with T2D shows a beneficial metabolic response. This response is defined by a reduction, within 6 months, of $\geq 11 \mathrm{mmol} / \mathrm{mol}$ (1\%-point) in glycated haemoglobin $\left(\mathrm{HbA}_{1 \mathrm{c}}\right)$ and a reduction of $\geq 3 \%$ in initial body weight [4]. In addition, NICE only recommends GLP-1RA initiation for patients with a body mass index (BMI) of $\geq 35 \mathrm{~kg} / \mathrm{m}^{2}$ and specific psychological or other medical problems associated with obesity, or with a $\mathrm{BMI}<35 \mathrm{~kg} / \mathrm{m}^{2}$ and significant occupational implications for insulin therapy, or body weight reductions that would benefit other significant obesity-related comorbidities [4].

Once-weekly (OW) subcutaneous semaglutide $0.5 \mathrm{mg}$ and $1.0 \mathrm{mg}$ is a GLP-1RA approved as an adjunct to diet and exercise for the treatment of adults with insufficiently controlled T2D $[12,13]$. In the SUSTAIN clinical trial 
programme, OW semaglutide demonstrated superior, clinically relevant glycaemic and body weight reductions versus placebo and a wide range of active comparators [9, 10, 14-20]. Although semaglutide was investigated in a broad range of subjects with T2D in these randomised controlled trials (RCTs), it is important to gather data on its use in the full spectrum of patients encountered in real-life clinical practice to complement and validate the results from RCTs [21].

The SURE programme, which consists of nine observational studies across 10 countries, aims to obtain real-world evidence (RWE) on the use of OW semaglutide in a wide range of patients with T2D across various countries. To date, the findings from SURE studies conducted in Canada [22], Denmark/Sweden [23] and Switzerland [24] have been reported. These studies reported reductions in $\mathrm{HbA}_{1 \mathrm{c}}$ and body weight from baseline to end of study (EOS) that are in line with those observed in the SUSTAIN programme. The SURE UK study aimed to evaluate the use of OW semaglutide in routine clinical practice in primary and secondary care settings in the UK.

\section{METHODS}

\section{Study Design}

This prospective, multicentre, open-label, observational study of approximately 30 weeks' duration was conducted to assess the use of OW semaglutide in adults with T2D attending eight specialist and 19 general practice clinics in the UK. The decision to initiate semaglutide treatment and any changes were made by the treating physician. Any changes to the semaglutide treatment regimen were to be recorded. The decision to include the patient in the study was made separately from the decision to initiate OW semaglutide. Diet and physical activity counselling and additional antihyperglycaemic treatments, prescribed at the physician's discretion, were permitted in accordance with routine clinical practice. Informed consent was obtained at the first (treatment initiation) visit at week 0 . The EOS visit was planned as the first visit that occurred between weeks 28 and 38 . However, due to the coronavirus disease 2019 (COVID-19) pandemic restrictions, patients were allowed to attend the EOS visit until week 52 . The study was conducted in compliance with the Declaration of Helsinki [25] and the Guidelines for Good Pharmacoepidemiology Practices [26]. All study materials were approved by the South West-Central Bristol Research Ethics Committee (reference number: 19/SW/ 0048), and all patients provided their informed consent prior to taking part in the study. This study is registered with ClinicalTrials.gov, NCT03876015. Novo Nordisk obtained the license to use the 8-item Morisky Medication Adherence Scale (MMAS-8) in this study.

\section{Study Population}

The first patient's first visit was on 1 May 2019 and the last patient's last visit on 12 August 2020. Inclusion criteria were: age $\geq 18$ years at the time of providing informed consent; diagnosis of $\mathrm{T} 2 \mathrm{D} \geq 12$ weeks prior to inclusion in the study; and the availability of documented $\mathrm{HbA}_{1 \mathrm{c}}$ measurements within 12 weeks prior to semaglutide treatment initiation. Key exclusion criteria were: previous participation in this study; incapacity, unwillingness or language barriers precluding adequate understanding; treatment with any investigational drug within 90 days prior to enrolment into the study; and hypersensitivity to semaglutide or to any of the excipients. The study duration of approximately 30 weeks was considered sufficient to initiate and optimise the semaglutide regimen and to obtain enough real-world data for the evaluation of the primary endpoint.

\section{Endpoints}

The primary endpoint was change in $\mathrm{HbA}_{1 \mathrm{c}}$ (mmol/mol and \%-point) from baseline to EOS. Secondary supportive endpoints included: changes in body weight (kg) and waist circumference $(\mathrm{cm})$ from baseline to EOS; the proportion of patients achieving an $\mathrm{HbA}_{1 \mathrm{c}}$ level of $<7 \%(53 \mathrm{mmol} / \mathrm{mol})$ at EOS; proportion of patients achieving weight reduction of $\geq 3 \%$ 
and $\geq 5 \%$; and the proportion of patients achieving the composite endpoint of an $\mathrm{HbA}_{1 \mathrm{c}}$ reduction of $\geq 1 \%$-point $(11 \mathrm{mmol} / \mathrm{mol})$ and a weight reduction of $\geq 3 \%$ at EOS. Finally, changes in scores for PROs from baseline to EOS were measured using the Diabetes Treatment Satisfaction Questionnaire status version (DTSQs) and the Short-Form 36 Health Survey version $2\left(\mathrm{SF}-36^{\circledR} \mathrm{v} 2\right)$. The DTSQs contains 6 items relating to absolute treatment satisfaction (two additional items relating to perception of hyperglycaemia and hypoglycaemia are not presented in the current analysis) [27]. Each item was scored on a 7-point scale, where $0=$ very dissatisfied and $6=$ very satisfied. The DTSQ change version (DTSQc) score was assessed at EOS. The DTSQc includes the same questions as the DTSQs but is designed to assess relative satisfaction with the current treatment compared with the previous treatment [28]. In the DTSQc, each of the 6 items about treatment satisfaction is scored on a scale from -3 (much less satisfied) to +3 (much more satisfied). The SF-36 ${ }^{\circledR}$ v2 questionnaire comprises 36 questions that are grouped into eight domains (physical functioning, bodily pain, role-physical, general health, vitality, social functioning, role-emotional and mental health). These domains are combined into two summary component scores: the physical component summary (PCS) and the mental component summary (MCS) [29]. Exploratory assessments included: the weekly dose of semaglutide at EOS; the level of patient-reported medication adherence at EOS (low, medium or high), which was based on the MMAS-8 [30-32]; the physician's assessment of whether or not clinical success had been achieved in relation to the reasons for initiating semaglutide treatment for a given individual; and the number of severe or documented hypoglycaemic episodes. Post-hoc assessments for change in $\mathrm{HbA}_{1 \mathrm{c}}$ (\%-point and $\mathrm{mmol} / \mathrm{mol}$ ) and body weight $(\mathrm{kg})$ were conducted in subgroups of patients: GLP-1RA naïve (i.e. had not received a GLP-1RA within 12 weeks of baseline); not reaching the target of $\geq 1 \%$-point $(11 \mathrm{mmol} / \mathrm{mol})$ and a weight reduction of $\geq 3 \%$ at EOS; and those with a baseline BMI $<35 \mathrm{~kg} / \mathrm{m}^{2}$ (the cut-off for recommending GLP-1RA initiation under current NICE guidelines) [4].

\section{Safety Information}

Serious adverse drug reactions (SADRs), fatal events, pregnancies in female patients, adverse events (AEs) in foetuses or newborn infants and all episodes of documented or severe hypoglycaemia were systematically collected. In addition, other AEs during the study period could be reported by physicians on a voluntary basis.

\section{Statistical Analyses}

Assuming a $40 \%$ drop-out rate, a sample size of 217 was calculated based on the criterion of $90 \%$ probability of obtaining a $95 \%$ confidence interval (CI) for mean change in $\mathrm{HbA}_{1 \mathrm{c}}$ from baseline to EOS with a half-width of $\leq 0.30$. This half-width limit was chosen to allow for robust evaluation of glycaemic control. The standard deviation of the mean change in $\mathrm{HbA}_{1 \mathrm{c}}$ was assumed to be 1.6 , based on the results of prior observational studies of a similar design [33-35]. Baseline characteristics and $\mathrm{AE}$ data were analysed using the full analysis set (FAS), which included all eligible patients who gave informed consent and initiated treatment with semaglutide. The primary analyses of the primary, secondary and exploratory assessments were performed using the effectiveness analysis set (EAS), which included all patients who completed the study (i.e. attended the EOS visit) and were receiving treatment with semaglutide at EOS, as assessed by their physician. Prespecified sensitivity analyses, based on the FAS, were performed to assess the impact of missing data in the primary analysis. The FAS included all patients who signed informed consent forms and initiated semaglutide treatment, regardless of any subsequent discontinuations or availability of $\mathrm{HbA}_{1 \mathrm{c}}$ measurements at EOS. An analysis of covariance model was used for the primary analyses of the primary endpoint and the analysis of the continuous secondary supportive endpoint. The sensitivity analyses were performed using a mixed model for repeated measurements on all patients in the FAS with at least one post-baseline $\mathrm{HbA}_{1 \mathrm{c}}$ measurement in the on-treatment and in-study periods. All statistical tests were performed as 
two-sided tests with a significance level of 0.05. No adjustments were made for multiple comparisons.

Due to the COVID-19 pandemic, patients were permitted to attend the EOS visit beyond week 38 (until week 52) from study initiation. An additional post-hoc sensitivity analysis was performed, restricted to patients with visit 6 within the original window, to investigate whether this delay affected the primary endpoint and the change in body weight from baseline to EOS.

\section{RESULTS}

\section{Patient Disposition and Baseline Characteristics}

Of the 221 patients who gave informed consent, six did not meet the eligibility criteria and were not enrolled into the study. The remaining 215 patients initiated treatment with semaglutide and were included in the FAS. In total, 34 patients attended the EOS visit after 38 weeks. A total of 44 patients did not complete the study and/or discontinued study treatment (Fig. 1). The 171 patients who completed the study on treatment comprised the EAS. The mean baseline $\mathrm{HbA}_{1 \mathrm{c}}$ of patients in the FAS was $74.0 \mathrm{mmol} / \mathrm{mol}(8.9 \%)$, and $20(9.3 \%)$ patients had $\mathrm{HbA}_{1 \mathrm{c}}<7 \%$ (Table 1). The majority $(90.2 \%)$ were white and most $(85.4 \%)$ had obesity, as defined by a BMI $\geq 30 \mathrm{~kg} / \mathrm{m}^{2}$; this was reflected in the mean baseline body weight $(107.8 \mathrm{~kg})$, BMI $\left(37.2 \mathrm{~kg} / \mathrm{m}^{2}\right)$ and waist circumference $(118.6 \mathrm{~cm})$ (Table 1$)$.

Hypertension and dyslipidaemia were the most prevalent cardiovascular comorbidities at baseline, affecting $67.0 \%$ and $42.3 \%$ of patients, respectively (Table 1 ). The majority of the 215 patients in the FAS (94.9\%) initiated semaglutide treatment at a dose of $0.25 \mathrm{mg}$ (Table 1). Physicians primarily initiated semaglutide to improve glycaemic control; weight reduction was a secondary reason (Table 1). No patients were receiving both a dipeptidyl peptidase- 4 inhibitor and a GLP-1RA (other than semaglutide) at baseline.

\section{Glycaemic Control}

In the EAS, the estimated mean change in $\mathrm{HbA}_{1 \mathrm{c}}$ from baseline to EOS was - 16.3 $\mathrm{mmol} / \mathrm{mol}[95 \%$ CI $-18.22, \quad-14.37$; $p<0.0001]$ or $-1.5 \%$-points [95\% CI -1.67 , $-1.31 ; p<0.0001$ ] (Table 2). The change in mean $\mathrm{HbA}_{1 \mathrm{c}}$ over the course of the study in the FAS is shown in Supplementary Fig. S1. Analysis of the FAS produced results for the overall population that were consistent with those for the EAS (Table 2), and the sensitivity analysis carried out on the FAS, including all $\mathrm{HbA}_{1 \mathrm{c}}$ measurements in the on-treatment observation period, supported the conclusions from the primary analysis. The results from the post-hoc sensitivity analysis, which was restricted to patients with visit 6 within the original visit window (week 28 to 38), were in line with the results of the primary analysis (Supplementary Table S1). At EOS, the proportion of patients achieving an $\mathrm{HbA}_{1 \mathrm{c}}$ level of $53 \mathrm{mmol} / \mathrm{mol}$ $(<7 \%)$ was $46.4 \%$ in the EAS (Fig. 2).

Among the 130 patients in the EAS who were GLP-1RA naïve, the estimated mean change in $\mathrm{HbA}_{1 \mathrm{c}}$ from baseline to EOS was comparable with that from the main analysis: - 17.1 $\mathrm{mmol} / \mathrm{mol} \quad(95 \%$ CI $-19.26,-15.01$; $p<0.0001)$ or $-1.6 \%$-points (95\% CI -1.76 , $-1.37 ; p<0.0001)$. The estimated mean change in $\mathrm{HbA}_{1 \mathrm{c}}$ from baseline to EOS in the EAS for the 82 patients who did not reach the target of a $\geq 1 \%$-point $\mathrm{HbA}_{1 \mathrm{c}}$ reduction and weight reduction of $\geq 3 \%$ at EOS was lower than in the complete EAS: - $10.1 \mathrm{mmol} / \mathrm{mol}$ (95\% CI $-12.92,-7.25 ; p<0.0001)$ or $-0.9 \%$-points $(95 \%$ CI $-1.18,-0.66 ; p<0.0001)$. There were 63 patients in the EAS who had a BMI of $<35$ $\mathrm{kg} / \mathrm{m}^{2}$ at baseline. Among these patients, the estimated mean change in $\mathrm{HbA}_{1 \mathrm{c}}$ from baseline to EOS was similar to that from the main analysis: $-17.2 \mathrm{mmol} / \mathrm{mol}$ (95\% CI - 20.22, $-14.19 ; p<0.0001)$ or $-1.6 \%$-points $(95 \% \mathrm{CI}$ $-1.85,-1.30 ; p<0.0001)$.

\section{Body Weight and Waist Circumference}

In the EAS, the estimated mean change in body weight from baseline to EOS was - $5.8 \mathrm{~kg}(95 \%$ 


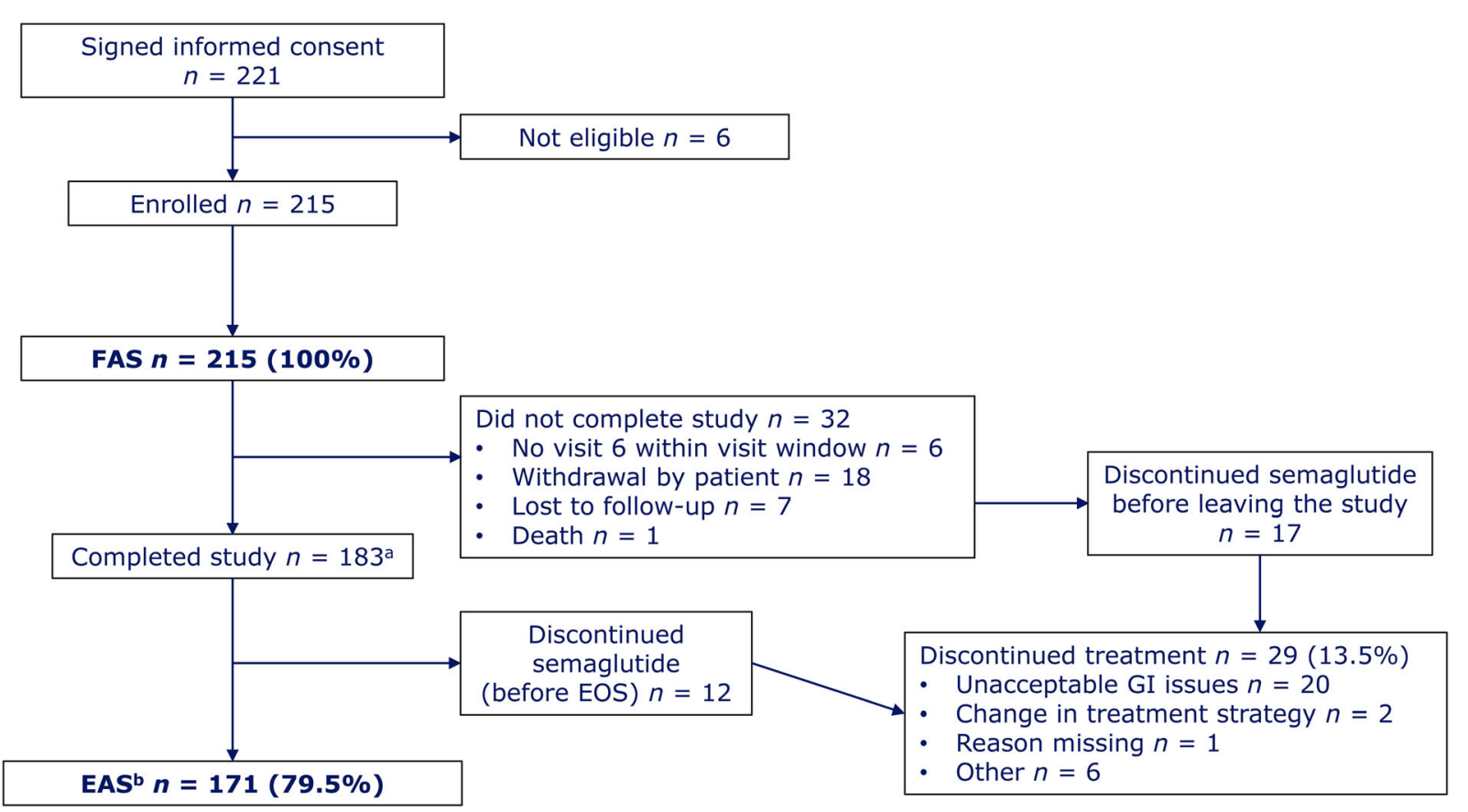

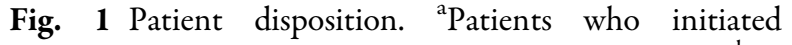
semaglutide treatment and attended the EOS visit; ${ }^{\mathrm{b}} 37$ (21.6\%) visits were carried out by telephone due to restrictions related to the coronavirus pandemic and 34

CI $-6.75,-4.94 ; p<0.0001)$, with similar results seen in the FAS (Table 2) and the EAS restricted to patients with a visit 6 within the original visit window (Supplementary Table S1). At EOS, the proportion of patients in the EAS achieving a weight reduction of $\geq 3 \%$ or $\geq 5 \%$ was $62.4 \%$ and $49.7 \%$, respectively (Fig. 2 ). For the change in waist circumference, the estimated mean change from baseline to EOS was $-5.8 \mathrm{~cm}(95 \% \mathrm{CI}-7.05,-4.55 ; p<0.0001)$; again, similar results were seen in the FAS (Table 2).

The estimated mean change in body weight from baseline to EOS was - $6.5 \mathrm{~kg}(95 \% \mathrm{CI}$ $-7.45,-5.48 ; p<0.0001)$ for the 130 GLP1RA-naïve patients, $-2.6 \mathrm{~kg}(95 \% \mathrm{CI}-3.73$, $-1.55 ; p<0.0001)$ for the 82 patients who did not reach the target of $\mathrm{a} \geq 1 \%$-point $\mathrm{HbA}_{1 \mathrm{c}}$ reduction and a weight reduction of $\geq 3 \%$ at EOS, and - $4.2 \mathrm{~kg}$ (95\% CI - 5.33, - 2.98; $p<0.0001)$ for the 60 patients who had a BMI of $<35 \mathrm{~kg} / \mathrm{m}^{2}$ at baseline (and weight reduction data available for analysis).
(19.9\%) EOS visits were performed outside of the 28- to 38 -week visit window. EAS effective analysis set, $E O S$ end of study, FAS full analysis set, $G I$ gastrointestinal

\section{Composite Endpoint}

The proportion of patients achieving the composite endpoint of $\mathrm{a} \geq 1 \%$-point $\mathrm{HbA}_{1 \mathrm{c}}$ reduction and a weight reduction of $\geq 3 \%$ was $39.7 \%$ (Fig. 2).

\section{Use of Semaglutide and Other Antihyperglycaemic Medications (EAS)}

The mean weekly dose of semaglutide at EOS was $0.73 \pm 0.31 \mathrm{mg}$. At EOS, one patient (0.6\%) was not receiving semaglutide at any dose (likely due to an interruption in treatment at the time of study completion), 29 (17.0\%) patients were receiving $0.25 \mathrm{mg}$ OW semaglutide; 47 (27.5\%) were receiving $0.5 \mathrm{mg}$; one $(0.6 \%)$ was receiving $0.75 \mathrm{mg}$ OW semaglutide; and $93(54.4 \%)$ were receiving $1.0 \mathrm{mg}$. Use of antihyperglycaemic medication either remained the same or declined from baseline to EOS, except that one additional patient reported the use of premixed insulin at EOS (Table 3). 
Table 1 Demographics and baseline characteristics

\begin{tabular}{|c|c|}
\hline \multicolumn{2}{|l|}{ Characteristic } \\
\hline Age, years & $59.0(11.6)$ \\
\hline \multicolumn{2}{|l|}{ Race, $n(\%)$} \\
\hline Asian & $8(3.7)$ \\
\hline Black or African American & $8(3.7)$ \\
\hline White & $194(90.2)$ \\
\hline Other & $5(2.3)$ \\
\hline Female, $n(\%)$ & $94(43.7)$ \\
\hline $\mathrm{HbA}_{1 \mathrm{c}}, \mathrm{mmol} / \mathrm{mol}$ & $74.0(18.3)$ \\
\hline $\mathrm{HbA}_{1 \mathrm{c}}, \%$ & $8.9(1.7)$ \\
\hline $\mathrm{HbA}_{1 \mathrm{c}}<53.0 \mathrm{mmol} / \mathrm{mol}(7.0 \%), n(\%)$ & $20(9.3)$ \\
\hline Fasting plasma glucose, $\mathrm{mmol} / \mathrm{L}^{\mathrm{a}}$ & $12.0(4.9)$ \\
\hline Body weight, $\mathrm{kg}^{\mathrm{b}}$ & $107.8(24.4)$ \\
\hline Body mass index, $\mathrm{kg} / \mathrm{m}^{2 \mathrm{c}}$ & $37.2(7.95)$ \\
\hline Waist circumference, $\mathrm{cm}^{\mathrm{d}}$ & $118.6(16.3)$ \\
\hline Diabetes duration, years & $11.0(6.3)$ \\
\hline $\mathrm{eGFR}, \mathrm{mL} / \mathrm{min} / 1.73 \mathrm{~m}^{2 \mathrm{e}}$ & $83.6(21.2)$ \\
\hline \multicolumn{2}{|l|}{ Comorbid conditions, $n(\%)$} \\
\hline Diabetic retinopathy & $60(27.9)$ \\
\hline Diabetic neuropathy & $25(11.6)$ \\
\hline Diabetic nephropathy & $21(9.8)$ \\
\hline \multicolumn{2}{|l|}{ Cardiovascular history, $n(\%)$} \\
\hline Hypertension & $144(67.0)$ \\
\hline Dyslipidaemia & $91(42.3)$ \\
\hline Coronary heart disease & $33(15.3)$ \\
\hline Heart failure & $9(4.2)$ \\
\hline Stroke & $6(2.8)$ \\
\hline Peripheral vascular disease & $5(2.3)$ \\
\hline \multicolumn{2}{|l|}{ Cardiovascular medications, $n$ (\%) } \\
\hline Cardiac therapy & $9(4.2)$ \\
\hline Antihypertensive agents & $18(8.4)$ \\
\hline Diuretics & $35(16.3)$ \\
\hline Vasoprotective agents & $1(0.5)$ \\
\hline Beta-blocking agents & $50(23.3)$ \\
\hline
\end{tabular}

Table 1 continued

\begin{tabular}{ll}
\hline Characteristic & $60(27.9)$ \\
\hline Calcium channel blockers & $130(60.5)$ \\
Agents acting on the renin-angiotensin & \\
system & $143(66.5)$ \\
Lipid-modifying agents & $39(18.1)$ \\
Platelet aggregation inhibitors & \\
Other antithrombotic agents & $10(4.7)$ \\
Reasons to initiate semaglutide, $n(\%))^{\mathrm{g}}$ & \\
Improve glycaemic control & $192(89.3)$ \\
Weight reduction & $155(72.1)$ \\
Issues with hypoglycaemia & $9(4.2)$ \\
Address cardiovascular risk factors & $42(19.5)$ \\
Simplify current treatment regimen & $37(17.2)$ \\
Convenience & $41(19.1)$ \\
Other & $10(4.7)$ \\
Starting dose of semaglutide, $n(\%)$ & \\
0.25 mg & $204(94.9)$ \\
0.5 mg & $8(3.7)$ \\
1.0 mg & $3(1.4)$ \\
\hline
\end{tabular}

Values are based on FAS $(n=215)$ unless otherwise noted. Data on continuous variables are mean (standard deviation) unless otherwise specified

$e G F R$ estimated glomerular filtration rate, $F A S$ full analysis set, $H b A_{1 c}$ glycated haemoglobin

a $n=26$

b $n=214$

c $n=213$

d $n=128$

e $n=193$

${ }^{\mathrm{f}}$ Excluding heparin

g More than one reason for initiating semaglutide could be selected

\section{Patient- and Physician-Reported Outcomes}

The estimated mean self-reported treatment adherence score, measured using the MMAS-8, was 6.4 at baseline and 7.1 at EOS, with $29.7 \%$ 
Table 2 Changes in primary and secondary endpoints from baseline to EOS in the EAS and FAS

\begin{tabular}{|c|c|c|c|c|c|c|c|c|c|c|}
\hline & \multicolumn{5}{|l|}{ EAS } & \multicolumn{5}{|l|}{ FAS } \\
\hline & $n^{\mathrm{b}}$ & $\begin{array}{l}\text { Baseline } \\
\text { mean (SD) }\end{array}$ & $\begin{array}{l}\text { Mean at } \\
\text { EOS }^{c}\end{array}$ & $\begin{array}{l}\text { Change from } \\
\text { baseline ( } 95 \% \mathrm{CI})\end{array}$ & $p$-value & $n^{\mathrm{b}}$ & $\begin{array}{l}\text { Baseline } \\
\text { mean }(S D)\end{array}$ & $\begin{array}{l}\text { Mean at } \\
\text { EOS }^{c}\end{array}$ & $\begin{array}{l}\text { Change from } \\
\text { baseline }(95 \% \mathrm{CI})\end{array}$ & $p$-value \\
\hline $\begin{array}{l}\mathrm{HbA}_{1 \mathrm{c}} \\
\qquad(\mathrm{mmol} / \mathrm{mol})\end{array}$ & 149 & $72.1(16.8)$ & 55.8 & $\begin{array}{l}-16.3 \\
(-18.22,-14.37)\end{array}$ & $<0.0001$ & 183 & $72.9(17.6)$ & 56.8 & $\begin{array}{l}-16.6 \\
(-18.41,-14.75)\end{array}$ & $<0.0001$ \\
\hline $\begin{array}{l}\mathrm{HbA}_{1 \mathrm{c}} \\
\quad \text { (\%-point) }\end{array}$ & 149 & $8.7(1.5)$ & 7.3 & $\begin{array}{l}-1.5 \\
(-1.67,-1.31)\end{array}$ & $<0.0001$ & 183 & $8.8(1.6)$ & 7.4 & $\begin{array}{l}-1.5 \\
(-1.68,-1.35)\end{array}$ & $<0.0001$ \\
\hline $\begin{array}{l}\text { Body } \\
\text { weight } \\
\text { (kg) }\end{array}$ & 149 & $\begin{array}{l}108.4 \\
(24.6)\end{array}$ & 102.6 & $\begin{array}{l}-5.8 \\
(-6.75,-4.94)\end{array}$ & $<0.0001$ & 161 & $\begin{array}{l}108.6 \\
(25.9)\end{array}$ & 103.0 & $\begin{array}{l}-5.6 \\
(-6.48,4.71)\end{array}$ & $<0.0001$ \\
\hline $\begin{array}{l}\text { Waist } \\
\text { circumference } \\
(\mathrm{cm})\end{array}$ & 118 & $\begin{array}{l}118.6 \\
(17.3)\end{array}$ & 112.8 & $\begin{array}{l}-5.8 \\
(-7.05,-4.55)\end{array}$ & $<0.0001$ & 128 & $\begin{array}{l}119.0 \\
\quad(17.4)\end{array}$ & 113.2 & $\begin{array}{l}-5.9 \\
(-7.07,-4.64)\end{array}$ & $<0.0001$ \\
\hline
\end{tabular}

Data shown are in-study values

$C I$ confidence interval, $E A S$ effectiveness analysis set, $E O S$ end of study, $F A S$ full analysis set, $H b A_{l c}$ glycated haemoglobin, $S D$ standard deviation

${ }^{a}$ Changes in $\mathrm{HbA}_{1 \mathrm{c}}$ in the FAS were determined using a mixed model for repeated measurements

b Numbers of patients refer to those included in the analysis

${ }^{c}$ Mean values for EOS are estimated means

and $48.1 \%$ of patients reporting high adherence, respectively (Table 4). Mean DTSQs score was 28.6 at baseline (observed) and 31.8 at EOS (estimated), resulting in an estimated change of 3.3 (95\% CI 2.39, 4.11; $p<0.0001$ ) (Supplementary Fig. S2). At EOS, the overall estimated mean DTSQc (change version) score was 14.4, indicating increased treatment satisfaction at EOS, and estimated changes from baseline to EOS in SF-36 ${ }^{\circledR}$ v2 PCS and MCS scores were 1.7 $(95 \%$ CI $0.44,2.89 ; p=0.008)$ and $0.8(95 \% \mathrm{CI}$ $-0.72,2.33 ; p=0.299$ ), respectively (Supplementary Fig. S2). According to their physicians, the majority of the patients $(85.4 \%)$ achieved clinical success at EOS in relation to the reason to initiate semaglutide treatment.

\section{Safety}

Overall, 157 AEs were reported in 76 patients in the FAS during the study (Table 5); the majority (137) of these events were considered non-serious. More than half of the 157 events (83) were gastrointestinal (Table 5). A total of 43 AEs in 22 patients (10.2\% of the FAS) led to discontinuation of treatment. Twenty serious AEs were reported in $13(6.0 \%)$ patients in the FAS. Twelve events in six $(2.8 \%)$ patients were judged by the physician to be probably or possibly related to semaglutide treatment (i.e. 12 SADRs) (Table 5): five SADRs resolved by EOS, one SADR resolved with sequelae (a pancreatitis event of moderate severity) and one SADR was not resolved by EOS. The status of the remaining five events was unknown at EOS. Of the eight serious AEs (in eight patients) deemed unlikely to be related to semaglutide treatment, one event with a fatal outcome was reported (sudden death). Documented hypoglycaemia was reported from baseline to EOS in 14 (6.5\%) patients in the EAS. There were no severe hypoglycaemic events reported.

\section{DISCUSSION}

In this SURE UK study, patients treated with semaglutide experienced statistically significant and clinically relevant reductions in $\mathrm{HbA}_{1 \mathrm{c}}$, 


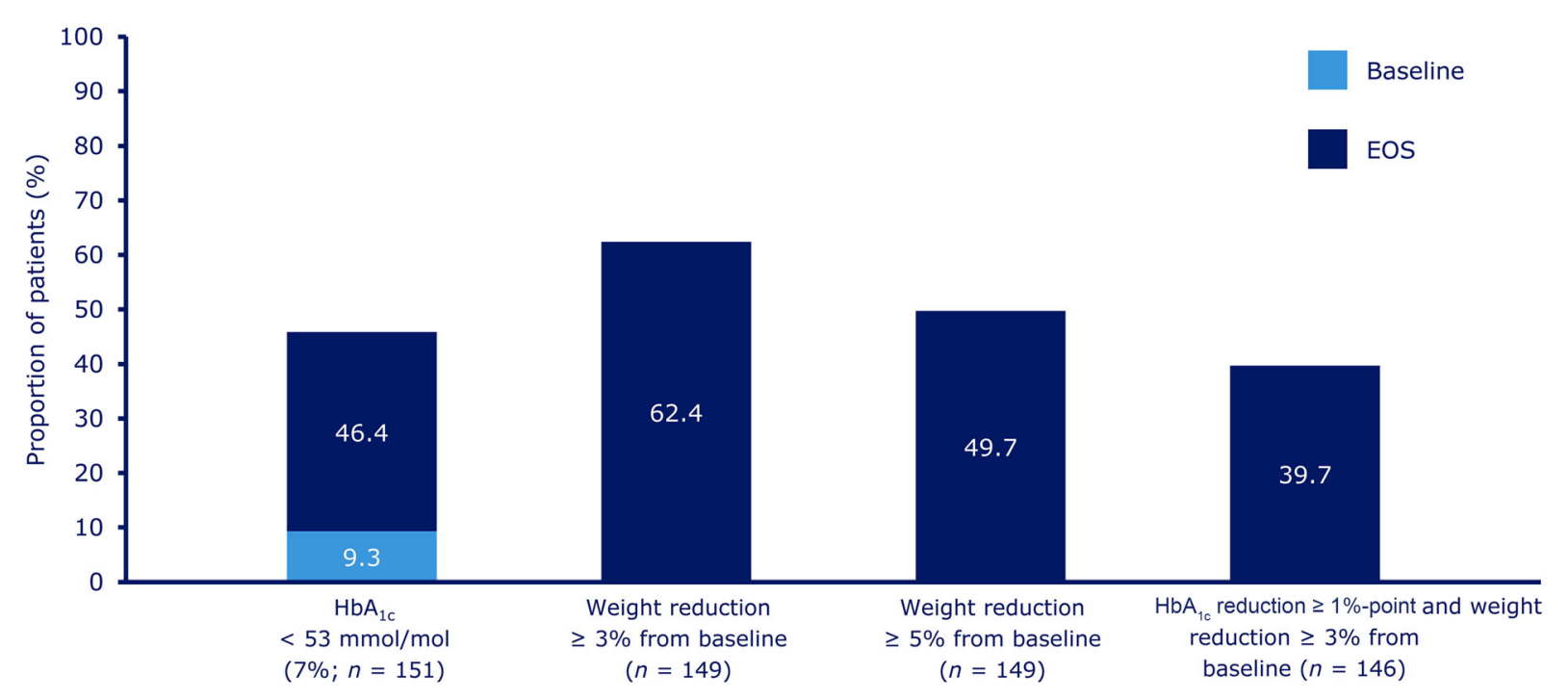

Fig. 2 Proportions of patients achieving $\mathrm{HbA}_{1 \mathrm{c}}$ targets and weight-reduction responses at EOS. Data are based on the effectiveness analysis set $(n=171) . n$ indicates the

body weight and waist circumference. These improvements were seen even in those patients who did not meet the NICE criteria for GLP-1RA continuation (reaching a reduction of $\geq 11 \mathrm{mmol} / \mathrm{mol}$ [1\%-point] in $\mathrm{HbA}_{1 \mathrm{c}}$ and a reduction of $\geq 3 \%$ of their initial body weight in 6 months) [4]. In addition, patients with a BMI of $<35 \mathrm{~kg} / \mathrm{m}^{2}$ also experienced clinically relevant reductions in $\mathrm{HbA}_{1 \mathrm{c}}$ and body weight; these patients would not typically be prescribed a GLP-1RA under current UK NICE guidelines (unless insulin therapy has significant occupational implications or body weight reductions benefit other significant obesity-related comorbidities) [4]. In SURE UK, PRO measures (treatment satisfaction and health-related quality of life) also improved from baseline to EOS.

There is some evidence of differences in the efficacy of incretin-based therapy between Asian and non-Asian populations [36]; however, because the majority $(90.2 \%)$ of patients in the SURE UK study were white, it was not possible to determine differences in mean outcome change by race.

To our knowledge, SURE UK is the first prospective RWE study of OW semaglutide in routine clinical practice in the UK. The glycaemic and weight reductions observed in the SURE UK study are consistent with those number of patients contributing to the analysis. EOS end of study, $H b A_{1 c}$ glycated haemoglobin

observed in the SURE studies carried out in Canada [22], Denmark/Sweden [23] and Switzerland [24]. Changes in $\mathrm{HbA}_{1 \mathrm{c}}$ from baseline to EOS were $-0.9,-1.2$ and $-0.8 \%$-points in SURE Canada, Denmark/Sweden and Switzerland, respectively, versus $-1.5 \%$-point in this study, and weight reductions in the SURE Canada [22], Denmark/Sweden [23] and Switzerland [24] studies were $4.3,5.4$ and $5.0 \mathrm{~kg}$, respectively, versus $5.8 \mathrm{~kg}$ in this study. The higher baseline $\mathrm{HbA}_{1 \mathrm{c}}(\%)$ in the SURE UK study (8.9 [1.7] compared with 8.1 [1.3] for SURE Canada, 7.9 [1.4] for Denmark/Sweden and 7.8 [1.4] for Switzerland) may have contributed to the greater reduction reported versus the other SURE studies. Patients in the SURE UK study also experienced $\mathrm{HbA}_{1 \mathrm{c}}$ and weight reductions that are consistent with those observed in the phase 3 RCTs in the SUSTAIN programme, where change in $\mathrm{HbA}_{1 \mathrm{c}}$ ranged from -1.1 to $-1.8 \%$-points and change in body weight ranged from -3.5 to $-6.5 \mathrm{~kg}$ with OW semaglutide versus comparators (placebo, sitagliptin, exenatide extended release, insulin glargine, dulaglutide, canagliflozin, liraglutide) $[6,9,10,14-20]$. This was despite the fact that approximately one in six patients in the SURE UK study were still receiving semaglutide at the initiation dose of $0.25 \mathrm{mg}$ at EOS, while patients 
Table 3 Concomitant antihyperglycaemic medications at baseline and EOS

\begin{tabular}{lll}
\hline $\begin{array}{l}\text { Antihyperglycaemic } \\
\text { medication, } \boldsymbol{n}(\%)\end{array}$ & $\begin{array}{l}\text { Baseline } \\
(\boldsymbol{n}=\mathbf{2 1 5})\end{array}$ & $\begin{array}{l}\text { End of in-study } \\
\text { observation } \\
\text { period }(\boldsymbol{n}=\mathbf{2 1 5})\end{array}$ \\
\hline Metformin & $167(77.7)$ & $165(76.7)$ \\
Sulphonylurea & $47(21.9)$ & $34(15.8)$ \\
Thiazolidinediones & $8(3.7)$ & $8(3.7)$ \\
DPP-4i & $36(16.7)$ & $11(5.1)$ \\
SGLT-2i & $83(38.6)$ & $79(36.7)$ \\
Other GLP-1RA & $27(12.6)$ & $1(0.5)$ \\
Basal insulin & $48(22.3)$ & $47(21.9)$ \\
Premixed insulin & $26(12.1)$ & $27(12.6)$ \\
Fast-acting insulin & $30(14.0)$ & $20(9.3)$ \\
Other glucose- & $2(0.9)$ & $2(0.9)$ \\
$\quad$ lowering drugs & & $11(5.1)$ \\
No medication & $5(2.3)$ & \\
\hline
\end{tabular}

Data are based on the full analysis set $(n=215)$

$D P P-4 i$ dipeptidyl peptidase- 4 inhibitor, EOS end of study, GLP-IRA glucagon-like peptide-1 receptor agonist, $S G L T-2 i$ sodium-glucose cotransporter-2 inhibitor

in the SUSTAIN RCTs would have been receiving semaglutide at the maintenance doses of 0.5 or $1.0 \mathrm{mg}$. The population studied in the SURE UK study was broader than those studied in the SUSTAIN RCTs; in particular, not all patients were GLP-1RA naive. In addition, the safety data reported in the SURE UK study were in line with the safety profile of semaglutide in the SUSTAIN RCTs $[6,9,10,14-20]$. No new safety concerns with semaglutide were identified in the current study. However, caution should be exercised when comparing the observations from the SURE UK study with the SUSTAIN RCT results due to differences in study design and baseline characteristics of the population. The baseline $\mathrm{HbA}_{1 \mathrm{c}}$ of $8.9 \%$ and body weight of $107.8 \mathrm{~kg}$ in SURE UK were higher than those for the populations of the SUSTAIN clinical trial programme,
Table 4 MMAS- 8 scores at baseline and EOS

\begin{tabular}{lll}
\hline MMAS-8 score & $\begin{array}{l}\text { Baseline } \\
(\boldsymbol{n}=\mathbf{1 6 5})\end{array}$ & $\begin{array}{l}\text { EOS } \\
(\boldsymbol{n}=\mathbf{1 5 4})\end{array}$ \\
\hline $\begin{array}{l}\text { Estimated mean } \\
(\mathrm{SD})\end{array}$ & $6.4(1.6)$ & $7.1(1.3)$ \\
$\begin{array}{l}\text { Level of adherence, } n(\%) \\
\text { High adherence }\end{array}$ & $49(29.7)$ & $74(48.1)$ \\
(score of 8$)$ & \\
$\begin{array}{l}\text { Medium adherence } \\
\text { (score of } 6 \text { to }<8)\end{array}$ & \\
Low adherence & $54(37.6)$ & \\
(score of $<6)$ & & $27(17.5)$ \\
\hline
\end{tabular}

Data are based on the effectiveness analysis set $(n=171)$. MMAS-8 is an 8-item structured, self-reported medication adherence measure with scores ranging from 0 (no adherence) to 8 (high adherence) [30-32]

$E O S$ end of study, MMAS-8 8-item Morisky Medication Adherence Scale, $S D$ standard deviation

Use of the ${ }^{\odot}$ MMAS is protected by US copyright laws. Permission for use is required. A license agreement is available from Donald E. Morisky, MMAS Research LLC, 14725 NE 20th St. Bellevue, WA 98007, or from dmorisky@gmail.com

in which baseline $\mathrm{HbA}_{1 \mathrm{c}}$ ranged from 8.1 to $8.4 \%$ and body weight from 89.5 to $95.8 \mathrm{~kg}$ [37].

Furthermore, the results of this study are consistent with those from other real-world studies. In the SPARE retrospective observational study of data from the Canadian LMC Diabetes Registry, 937 GLP-1RA-naïve adults with T2D who initiated therapy with semaglutide experienced reductions in $\mathrm{HbA}_{1 \mathrm{c}}$ and body weight of $1 \%$-point and $3.9 \mathrm{~kg}$, respectively ( $p<0.0001$ for both reductions) at 4.9 months' follow-up [38]. In an observational prospective analysis of RWE of the GLP-1RA dulaglutide that was carried out in 182 patients with T2D in Clyde, UK, statistically significant reductions in $\mathrm{HbA}_{1 \mathrm{c}}$ at $3 \mathrm{months}(14.29 \mathrm{mmol} / \mathrm{mol})$ and 6 months $(13.68 \mathrm{mmol} / \mathrm{mol})$ were noted. The reduction in weight observed in this study was $2.06 \mathrm{~kg}$ at 3 months and $3.46 \mathrm{~kg}$ at 6 months [39]. 
Table 5 AEs and severe or documented hypoglycaemic episodes

\begin{tabular}{|c|c|c|}
\hline & $\begin{array}{l}\text { Patients, } \\
n(\%)\end{array}$ & $\begin{array}{l}\text { Events, } \\
n\end{array}$ \\
\hline All AEs & $76(35.3)$ & 157 \\
\hline Serious AEs & $13(6.0)$ & 20 \\
\hline \multicolumn{3}{|l|}{ Severity of AEs } \\
\hline Mild & $55(25.6)$ & 99 \\
\hline Moderate & $27(12.6)$ & 45 \\
\hline Severe & $8(3.7)$ & 13 \\
\hline Serious adverse drug reactions & $6(2.8)$ & 12 \\
\hline $\begin{array}{l}\text { AEs leading to treatment } \\
\text { discontinuation }\end{array}$ & $22(10.2)$ & 43 \\
\hline Gastrointestinal AEs & $51(23.7)$ & 83 \\
\hline $\begin{array}{l}\text { Severe or documented } \\
\text { hypoglycaemia between baseline } \\
\text { and EOS }\end{array}$ & $14(6.5)$ & 29 \\
\hline
\end{tabular}

Data are based on the full analysis set $(n=215)$, except for the hypoglycaemia data, which are based on the effectiveness analysis set $(n=171)$

$A E$ adverse event, $E O S$ end of study

The population of a real-world study is more diverse than that included in an RCT, and the variety of characteristics and demographics of the patient population of SURE UK is an inherent strength of the study. Additionally, a real-world study assesses the use of the drug in routine clinical practice, as opposed to the controlled settings applied in an RCT. Other strengths of the study include the long duration and the inclusion of both primary and secondary care settings in the UK. Lastly, the estimated mean changes in $\mathrm{HbA}_{1 \mathrm{c}}$ and body weight from baseline to EOS and the associated 95\% CIs for the post-hoc analysis were similar to those seen in primary analysis, corroborating the robustness of the results.

There are several limitations to the SURE UK study, which are related to its design. As with the other SURE observational studies, the objective of the SURE UK study was descriptive rather than comparative: to enhance the understanding of the use of semaglutide in a real-world setting of a heterogeneous population of patients in routine clinical practice in the UK. Therefore, information on a group of patients receiving a comparator was not collected in this study. In the absence of a randomised comparator group, we cannot rule out the impact of prognostic factors and regression to the mean, and we cannot directly infer the estimated changes in the outcomes as causal effects of study treatment. However, the magnitudes of the changes in $\mathrm{HbA}_{1 \mathrm{c}}$ and body weight observed in SURE UK are consistent with those reported for the SUSTAIN trials $[6,9,10,14-20]$. The primary analysis based on patients continuing treatment to EOS could have led to overestimations of the reductions in $\mathrm{HbA}_{1 \mathrm{c}}$ and body weight. Secondary analyses of FAS that were not restricted to patients finalising the study on treatment supported the results of the primary analysis, which suggests that large overestimation of treatment outcomes is unlikely. In addition, due to the COVID-19 pandemic restrictions, patients were allowed to attend the EOS visit until week 52, rather than at weeks $28-38$ as originally planned. However, the results of a post-hoc sensitivity analysis that excluded EOS visits outside the 28- to 38-week window support the main findings, suggesting that this did not have a major impact on the results. Finally, the data were collected during routine clinical practice rather than through mandatory assessments at prespecified time points, which may have affected the robustness and completeness of the dataset.

\section{CONCLUSION}

In the SURE UK real-world study, semaglutide treatment was associated with clinically relevant glycaemic control and body weight reductions and improvements in other clinical parameters in a broad spectrum of patients with T2D across both specialist and primary care settings in the UK. Semaglutide was well tolerated, with relatively low rates of treatment discontinuation. The reported safety data raised no 
new concerns. These results support the use of OW semaglutide in routine clinical practice in adults with T2D in the UK. Future RWE from different settings and geographic locations will provide more information for clinicians and decision makers on the clinical use of OW semaglutide for patients with T2D.

\section{ACKNOWLEDGEMENTS}

We thank all the participants, investigators and trial-site staff.

Funding. This work was sponsored by Novo Nordisk A/S and Novo Nordisk A/S funded the journal's Rapid Service Fee.

Medical Writing, Editorial and Other Assistance. We thank Andreas Ross Kirk and Umut Erhan (Novo Nordisk A/S, Søborg, Denmark) for their review and input to the manuscript, and Catherine Starling (AXON Communications, UK) for medical writing and editorial assistance (funded by Novo Nordisk $\mathrm{A} / \mathrm{S})$.

Authorship. All named authors meet the International Committee of Medical Journal Editors criteria for authorship for this article, take responsibility for the integrity of the work as a whole and have given their approval for this version to be published.

Authors' Contributions. All authors contributed to the interpretation of data, the writing and critical revision of manuscript at all stages of development. All authors approved the final submitted manuscript. In addition, Dr Heather Bell contributed to data collection; Dr Andrei-Mircea Catarig to the study design, study conduct and data curation; Miss Alice Clark to the study conduct, data curation and statistical analysis; Dr Karan Bozkurt to data collection and data curation; Dr Alena Machell to data collection and data curation, and Professor Thozhukat Sathyapalan to the study conduct and data collection.
Prior Presentation. An oral and poster presentation of the results of the SURE UK study were presented at the Diabetes UK (DUK) Professional Conference, which took place online on 19-30 April 2021 [40].

Disclosures. Dr Patrick Holmes reports personal fees from AstraZeneca, Boehringer Ingelheim, Eli Lilly, Napp and Novo Nordisk, outside the submitted work. Dr Heather Bell reports payment or honoraria for lectures, presentations, speakers' bureaus, manuscript writing or educational events from AstraZeneca, Boehringer Ingelheim, Eli Lilly, Napp and Novo Nordisk outside the submitted work. Miss Alice Clark and Dr Andrei-Mircea Catarig are employees of Novo Nordisk A/S, Søborg, Denmark. Dr AndreiMircea Catarig owns stock in the company. Dr Karan Bozkurt is an employee of Novo Nordisk Ltd, London, UK, and also owns stock in the company. Dr Alena Machell has no disclosures to report. Professor Thozhukat Sathyapalan reports grants from Abbott and Novo Nordisk outside the submitted work.

Compliance with Ethics Guidelines. This study was conducted in accordance with the Declaration of Helsinki and the Guidelines for Good Pharmacoepidemiology Practices. All patients provided their prior, informed consent for participation in this study. Study materials were approved by the South West-Central Bristol Research Ethics Committee (reference number: 19/SW/0048). Novo Nordisk obtained the license to use the MMAS-8 in this study.

Data Availability. The datasets generated during and/or analysed during the current study are available from the corresponding author on reasonable request.

Open Access. This article is licensed under a Creative Commons Attribution-NonCommercial 4.0 International License, which permits any non-commercial use, sharing, adaptation, distribution and reproduction in any medium or format, as long as you give appropriate credit to the original author(s) and the source, provide a link to the Creative Commons licence, and indicate if changes were made. The images or 
other third party material in this article are included in the article's Creative Commons licence, unless indicated otherwise in a credit line to the material. If material is not included in the article's Creative Commons licence and your intended use is not permitted by statutory regulation or exceeds the permitted use, you will need to obtain permission directly from the copyright holder. To view a copy of this licence, visit http://creativecommons.org/licenses/by$\mathrm{nc} / 4.0 /$.

\section{REFERENCES}

1. Diabetes UK. Number of people with diabetes reaches 4.8 million. 2019. https://www.diabetes. org.uk/about_us/news/diabetes-prevalence-2019. Accessed 17 Aug 2021.

2. Davies MJ, D'Alessio DA, Fradkin J, et al. Management of hyperglycaemia in type 2 diabetes, 2018. A consensus report by the American Diabetes Association (ADA) and the European Association for the Study of Diabetes (EASD). Diabetologia. 2018;61: 2461-98.

3. American Diabetes Association. Standards of medical care in diabetes-2021. Diabetes Care. 2021;44(Suppl 1):S1-232.

4. National Institute for Health and Care Excellence. Type 2 diabetes in adults: management [NG28] 2015 (NICE clinical guidelines, updated December 2020). https://www.nice.org.uk/guidance/ng28. Accessed 17 Aug 2021.

5. Buse JB, Wexler DJ, Tsapas A, et al. 2019 Update to: management of hyperglycaemia in type 2 diabetes, 2018. A consensus report by the American Diabetes Association (ADA) and the European Association for the Study of Diabetes (EASD). Diabetologia. 2020;63:221-8.

6. Marso SP, Bain SC, Consoli A, et al. Semaglutide and cardiovascular outcomes in patients with type 2 diabetes. N Engl J Med. 2016;375:1834-44.

7. Marso SP, Daniels GH, Brown-Frandsen K, et al. Liraglutide and cardiovascular outcomes in type 2 diabetes. N Engl J Med. 2016;375:311-22.

8. Gerstein HC, Colhoun HM, Dagenais GR, et al. Dulaglutide and cardiovascular outcomes in type 2 diabetes (REWIND): a double-blind, randomised placebo-controlled trial. Lancet. 2019;394:121-30.
9. Pratley RE, Aroda VR, Lingvay I, et al. Semaglutide versus dulaglutide once weekly in patients with type 2 diabetes (SUSTAIN 7): a randomised, openlabel, phase $3 \mathrm{~b}$ trial. Lancet Diabetes Endocrinol. 2018;6:275-86.

10. Capehorn MS, Catarig AM, Furberg JK, et al. Efficacy and safety of once-weekly semaglutide $1.0 \mathrm{mg}$ vs once-daily liraglutide $1.2 \mathrm{mg}$ as add-on to $1-3$ oral antidiabetic drugs in subjects with type 2 diabetes (SUSTAIN 10). Diabetes Metab. 2020;46:100-9.

11. Prasad-Reddy L, Isaacs D. A clinical review of GLP-1 receptor agonists: efficacy and safety in diabetes and beyond. Drugs Context. 2015;4:212283.

12. European Medicines Agency. Ozempic $0.5 \mathrm{mg}$ solution for injection in pre-filled pen. Summary of product characteristics. 2020. https://www.ema. europa.eu/en/documents/product-information/ ozempic-epar-product-information_en.pdf. Accessed 17 Aug 2021.

13. Food and Drug Administration. Ozempic $0.5 \mathrm{mg} /$ $1.0 \mathrm{mg}$ injection. Prescribing information. 2020. https://www.accessdata.fda.gov/drugsatfda_docs/ label/2020/209637s003lbl.pdf. Accessed 17 Aug 2021.

14. Sorli C, Harashima SI, Tsoukas GM, et al. Efficacy and safety of once-weekly semaglutide monotherapy versus placebo in patients with type 2 diabetes (SUSTAIN 1): a double-blind, randomised, placebocontrolled, parallel-group, multinational, multicentre phase 3a trial. Lancet Diabetes Endocrinol. 2017;5:251-60.

15. Ahmann AJ, Capehorn M, Charpentier G, et al. Efficacy and safety of once-weekly semaglutide versus exenatide ER in subjects with type 2 diabetes (SUSTAIN 3): a 56-week, open-label, randomized clinical trial. Diabetes Care. 2018;41:258-66.

16. Ahrén B, Masmiquel L, Kumar H, et al. Efficacy and safety of once-weekly semaglutide versus once-daily sitagliptin as an add-on to metformin, thiazolidinediones, or both, in patients with type 2 diabetes (SUSTAIN 2): a 56-week, double-blind, phase 3a, randomised trial. Lancet Diabetes Endocrinol. 2017;5:341-54.

17. Aroda VR, Bain SC, Cariou B, et al. Efficacy and safety of once-weekly semaglutide versus once-daily insulin glargine as add-on to metformin (with or without sulfonylureas) in insulin-naive patients with type 2 diabetes (SUSTAIN 4): a randomised, open-label, parallel-group, multicentre, multinational, phase 3a trial. Lancet Diabetes Endocrinol. 2017;5:355-66.

18. Rodbard HW, Lingvay I, Reed J, et al. Semaglutide added to basal insulin in type 2 diabetes (SUSTAIN 
5): a randomized, controlled trial. J Clin Endocrinol Metab. 2018;103:2291-301.

19. Lingvay I, Catarig AM, Frias JP, et al. Efficacy and safety of once-weekly semaglutide versus daily canagliflozin as add-on to metformin in patients with type 2 diabetes (SUSTAIN 8): a double-blind, phase $3 \mathrm{~b}$, randomised controlled trial. Lancet Diabetes Endocrinol. 2019;7:834-44.

20. Zinman B, Bhosekar V, Busch R, et al. Semaglutide once weekly as add-on to SGLT-2 inhibitor therapy in type 2 diabetes (SUSTAIN 9): a randomised, placebo controlled trial. Lancet Diabetes Endocrinol. 2019;7:356-67.

21. de Lusignan S, Crawford L, Munro N. Creating and using real-world evidence to answer questions about clinical effectiveness. J Innov Health Inform. 2015;22:368-73.

22. Yale JF, Catarig A-M, Erhan U, et al. Use of onceweekly semaglutide in patients with type 2 diabetes in routine clinical practice: results from the SURE Canada multicenter, prospective, observational study. Diabetes Obes Metab. 2021;23:2269-78.

23. Ekberg NR, Bodholdt U, Catarig A-M, et al. Realworld use of once-weekly semaglutide in patients with type 2 diabetes: results from the SURE Denmark/Sweden multicentre, prospective, observational study. Prim Care Diabetes. 2021;S17519918(21)00112-1.

24. Rudofsky G, Catarig AM, Favre L, et al. Real-world use of once-weekly semaglutide in patients with type 2 diabetes: Results from the SURE Switzerland multicentre, prospective, observational study. Diabetes Res Clin Pract. 2021;178:108931.

25. World Medical Association. World Medical Association Declaration of Helsinki: ethical principles for medical research involving human subjects. JAMA. 2013;310:2191-4.

26. International Society for Pharmacoepidemiology. Guidelines for good pharmacoepidemiology practices (GPP). Revision 2, April 2007. Bethesda, MD: ISPE; 2007. https://www.pharmacoepi.org/ resources/policies/guidelines-08027. Accessed 20 Sept 2021.

27. Bradley C. Handbook of psychology and diabetes: a guide to psychological measurement in diabetes research and management, vol. xiii. Langhorne: Harwood Academic Publishers; 1994. p. 424.

28. Bradley C, Plowright R, Stewart J, Valentine J, Witthaus E. The Diabetes Treatment Satisfaction Questionnaire change version (DTSQc) evaluated in insulin glargine trials shows greater responsiveness to improvements than the original DTSQ. Health Qual Life Outcomes. 2007;5:57.

29. Ware JE Jr, Sherbourne CD. The MOS 36-item shortform health survey (SF-36). I. Conceptual framework and item selection. Med Care. 1992;30: 473-83.

30. Morisky DE, Ang A, Krousel-Wood M, Ward HJ. Predictive validity of a medication adherence measure in an outpatient setting. J Clin Hypertens (Greenwich). 2008;10:348-54.

31. Krousel-Wood M, Islam T, Webber LS, Re RN, Morisky DE, Muntner P. New medication adherence scale versus pharmacy fill rates in seniors with hypertension. Am J Manag Care. 2009;15:59-66.

32. Morisky DE, DiMatteo MR. Improving the measurement of self-reported medication nonadherence: final response. J Clin Epidemiol. 2011;64: 258-63.

33. Gautier JF, Martinez L, Penfornis A, et al. Effectiveness and persistence with liraglutide among patients with type 2 diabetes in routine clinical practice-EVIDENCE: a prospective, 2-year followup, observational, post-marketing study. Adv Ther. 2015;32:838-53.

34. Buysman EK, Liu F, Hammer M, Langer J. Impact of medication adherence and persistence on clinical and economic outcomes in patients with type 2 diabetes treated with liraglutide: a retrospective cohort study. Adv Ther. 2015;32:341-55.

35. Lee WC, Dekoven M, Bouchard J, Massoudi M, Langer J. Improved real-world glycaemic outcomes with liraglutide versus other incretin-based therapies in type 2 diabetes. Diabetes Obes Metab. 2014;16:819-26.

36. Chou CA, Chuang SF. Evaluation of the efficacy of low-dose liraglutide in weight control among Taiwanese non-diabetes patients. J Diabetes Investig. 2020;11:1524-31.

37. Goldenberg RM, Steen O. Semaglutide: review and place in therapy for adults with type 2 diabetes. Can J Diabetes. 2019;43:136-45.

38. Brown RE, Bech PG, Aronson R. Semaglutide once weekly in people with type 2 diabetes: real-world analysis of the Canadian LMC diabetes registry (SPARE study). Diabetes Obes Metab. 2020;22: 2013-20.

39. Pacitti S, Smith C, Deosaran J. Observational prospective analysis of real-world experience of glucagon-like peptide-1 receptor agonist 
dulaglutide in patients with type 2 diabetes in Clyde (poster P357). Diabet Med. 2018;35(Suppl 1): 147-8.

40. Holmes P, Catarig AM, Clark A, Erhan U, Sathyapalan T. Real-world use of once-weekly semaglutide in type 2 diabetes: results from the SURE UK study. Oral presentation at Diabetes UK (DUK) Professional Conference, 19-30 April 2021, online, Abstract A21. 